\title{
OTITIS EKSTERNA AKIBAT INFESTASI Otodectes cynotis PADA KUCING DOMESTIK LONG HAIR
}

\author{
Erfan Andrianto Aritonang ${ }^{*}$, Nindya Kusumawati ${ }^{2}$, Alvin Febrianth ${ }^{2}$, Dinda Mahardika ${ }^{2}$, Ady \\ Kurnianto $^{3}$ \\ ${ }^{1}$ Mahasiswa Pendidikan Profesi Dokter Hewan, Fakultas Kedokteran Hewan \\ Universitas Wijaya Kusuma Surabaya \\ *email: erfanaritonang@gmail.com \\ 2 Klinik Tabby Pet Care \\ ${ }^{3}$ Laboratorium Klinik Veteriner, Fakultas Kedokteran Hewan \\ Universitas Wijaya Kusuma Surabaya
}

\begin{abstract}
A two years old male cat domestic long hair was brought to the Tabby Pet Care clinic with the owner's complaint that the cat often scratches his right and left ears. The results of clinical examination showed scratching marks on the pinna, blackish yellow, wet, and smelly ear serumen on the ear canal. Investigations include microscopic examination of ear swabs and cerumen swab cytology. Ear swab examination results observed the presence of Otodectes cynotis and Otodectes cynotis eggs. The results of cytological examination of cerumen swabs using the rapid stain method were observed to have bacterial infections in the form of bacilli, coccus, and the presence of neutrophil infiltration. Based on clinical symptoms and the results of investigations, the patient was diagnosed with external otitis with a fausta prognosis. Treatment of otitis externa is carried out with topical therapy Ilium ${ }^{\circledR}$ ear drop. Therapy is carried out for seven days. On the eighth day the patient was declared cured and allowed to go home.
\end{abstract}

Keywords: Domestic long hair cat, external otitis, Otodectes cynotis

\section{PENDAHULUAN}

Otitis eksterna adalah keadaan inflamasi pada saluran telinga eksternal dan menjadi kasus yang paling sering ditemukan pada praktisi hewan kecil. Inflamasi saluran telinga eksternal terjadi karena adanya kolonisasi mikroorganisme (bakteri, jamur, atau parasit) yang berdampak pada kerusakan jaringan lokal telinga sehingga memicu reaksi inflamasi. Infestasi Otodectes cynotis merupakan penyebab paling umum atau sebesar 50\% $84 \%$ terjadinya otitis eksterna pada kucing (Kartini et al., 2017; Acar dan Yipel, 2016).

Otodectes cynotis merupakan tungau dengan predileksi disaluran telinga eksternal yang dapat ditemukan pada kucing, anjing, musang, dan rubah. Otodectes cynotis hidup dengan memakan debris superfisial saluran telinga eksternal dan serumen telinga. Dampak yang ditimbulkan akibat infestasi Otodectes cynotis pada saluran telinga eksternal adalah iritasi akibat reaksi hipersensitifitas earmites, eritrema, dan pruritus. Penularan dapat terjadi melalui kontak langsung (Siagian dan Fikri, 2019; da Silva et al., 2020; Taenzler, 2018).
Diagnosis otitis eksterna dapat dilakukan dengan berbagai metode, meliputi inspeksi langsung dengan otoskop atau pengamatan earmites secara mikroskopik, sitologi ear serumen, kultur dan uji sensitivitas mikroorganisme, serta dan radiologi. Terapi yang diberikan berdasar pada penyebab utama otitis eksterna. Terapi topikal dapat menggunakan preparat yang mengandung polimixin-B, clotrimazole, imidazole, miconazole, dexamethasone, chlorhexidine, atau povidone iodine. Antibiotik sistemik dapat menggunakan amoxicilin clavulanic acid atau enrofloxacin. Ivermectin, salamectin serta golongan phyretroid dapat digunakan apabila penyebab utamanya earmites (Silva et al., 2020; Kartini et al., 2017). Tujuan penulisan studi kasus ini adalah sebagai referensi metode penegakan diagnosa serta terapi otitis eksterna pada kucing.

\section{KASUS}

Kucing domestik long hair jantan berumur 2 tahun dibawa ke klinik Tabby Pet Care oleh owner. Berat badan kucing 3,35 kg 
dan suhu $38,9^{\circ} \mathrm{C}$. Keluhan dari owner adalah kucing sering menggaruk telinga kanan dan kiri. Kucing dipelihara secara semi-indoor dan telah divaksinasi. Gejala klinis pada telinga yaitu teramati adanya kotoran telinga bewarna kuning kehitaman, basah, dan berbau, serta adanya bekas garukkan pada pinna.

Pemeriksaan penunjang meliputi ear swab dan sitologi ear serumen. Metode pemeriksaan ear swab dilakukan dengan cara mengoleskan cotton bud yang sudah terdapat ear serumen pasien pada object glass kemudian ditetesi $\mathrm{KOH} 10 \%$ dan ditutup dengan cover glass, lalu diperiksa dibawah mikroskop dengan perbesaran 10x. Metode pemeriksaan sitologi ear serumen dilakukan dengan cara mengoleskan cotton bud ear swab pada object glass, kemudian dilakukan pewarnaan menggunakan metode rapid stain. Larutan rapid stain terdiri dari etanol sebagai fiksator, serta eosin dan methylen blue sebagai pewarna. Hasil pewarnaan lalu diperiksa di bawah mikroskop dengan perbesaran 1000x.

Hasil pemeriksaan ear swab teramati adanya Otodectes cynotis dan telur Otodectes cynotis (Gambar 1). Hasil pemeriksaan sitologi ear serumen teramati adanya bakteri bentuk kokus, basil, serta infiltrasi sel radang neutrofil (Gambar 2). Berdasarkan hasil pemeriksaan gejala klinis dan pemeriksaan penunjang, pasien didiagnosa mengalami otitis eksterna dengan prognosa fausta. Pengobatan dilakukan dengan cara membersihkan telingga pasien dengan cotton bud, lalu diberikan terapi topikal Ilium ${ }^{\circledR}$ ear drop tiga tetes dua kali sehari selama tujuh hari. Hari kedelapan pasien dinyatakan sembuh dan diperbolehkan pulang.

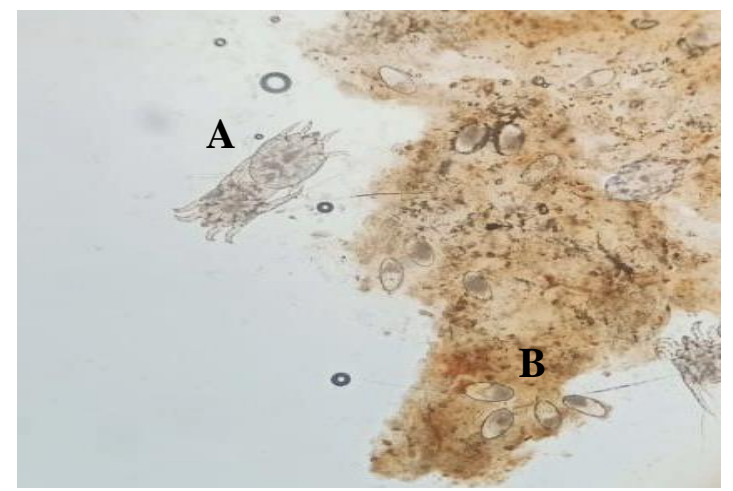

Gambar 1. Hasil pemeriksaan ear swab. Teramati adanya Otodectes cynotis (A) dan telur Otodectes cynotis (B)

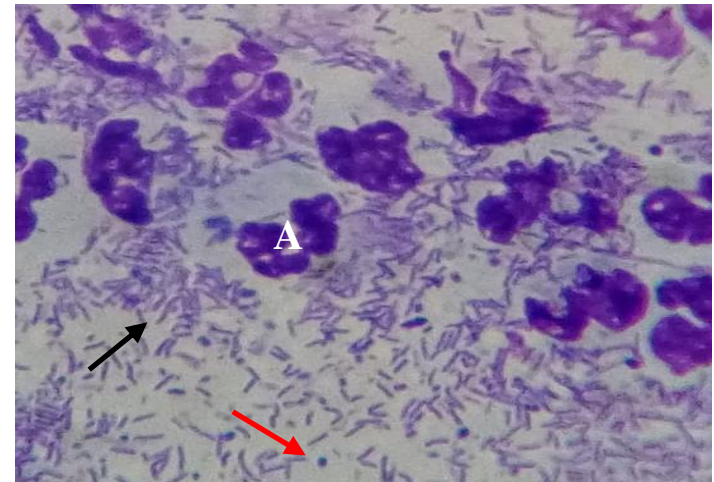

Gambar 2. Hasil pemeriksaan sitologi ear serumen teramati adanya bakteri bentuk kokus (panah merah), basil (panah hitam), serta infiltrasi sel radang neutrofil (A)

\section{DISKUSI}

Otitis eksterna merupakan suatu bentuk keradangan pada saluran telinga eksternal. Kasus ini sangat sering terjadi pada anjing dan kucing dengan beberapa faktor predisposisi yang meliputi struktur anatomi, kondisi imunologi dan endokrinologi, adanya benda asing, trauma, serta efek samping dari terapi tertentu. Infestasi Otodectes cynotis merupakan penyebab paling umum atau sebesar 50\% - 84\% terjadinya otitis eksterna pada kucing. Adanya infestasi Otodectes cynotis pada saluran telinga eksternal ditandai dengan adanya serumen bewarna kehitaman.

Kejadian otitis eksterna dapat diperparah akibat adanya infeksi sekunder oleh bakteri ataupun jamur. Bakteri kokus yang umum ditemukan pada kasus otitis eksterna adalah Staphylococcus intermedius atau Staphylococcus intermedius, sedangkan bakteri basil yang umum ditemukan Pseudomonas sp. Infeksi bakteri ditandai dengan adanya cairan purulen pada saluran telinga (Acar dan Yipel, 2016; Kartini et al., 2017; Silva, 2020; Taenzler, 2018). Teori ini sejalan dengan gejala klinis yang muncul pada telinga pasien yaitu berupa adanya kotoran telinga bewarna kuning kehitaman, basah, dan berbau. Hal ini kemudian dikonfirmasi melalui hasil pemeriksaan penunjang ear swab dan sitologi ear serumen pasien, yaitu ditemukannya infestasi Otodectes cynotis dan bakteri basil, kokus, serta adanya infiltrasi sel radang neutrofil.

Kejadian otitis eksterna dapat terjadi pada semua tingkatan usia kucing serta penularan dapat terjadi melalui kontak langsung antara 
kucing dengan otitis eksterna dengan kucing sehat. Kondisi lingkungan yang kurang bersih berdampak pada kebersihan kucing, sehingga akan menganggu kesehatan kucing. Hal ini sesuai dengan kasus, yaitu kucing dipelihara secara semi-indoor. Kucing yang dipelihara secara semi-indoor akan memiliki kemungkinan yang lebih besar terjadinya kolinisasi mikroorganisme dari lingkungan serta tertular dari kucing lain yang mengalami otitis eksterna.

Pengamatan progres kesembuhan otitis eksterna pasien dilakukan pada hari ke- 0 , hari ke-3 terapi, hari ke-5 terapi, dan hari ke-7 terapi. Hari ke-0 merupakan hari dimana hewan dibawa ke klinik dan dilakukan pemeriksaan awal. Progres kesembuhan otitis eksterna pasien ditinjau dari kondisi telinga bagian luar dengan inspeksi langsung serta skoring jumlah Otodectes cynotis dengan pemeriksaan ear swab. Pengamatan progres kesembuhan yang ditinjau dari kondisi telinga bagian luar yaitu pada hari ke-0, teramati adanya kotoran telinga bewarna kuning kehitaman, basah, dan berbau serta kondisi rambut disekitar telinga basah (Gambar 3). Aksi kucing menggaruk telinga juga sangat aktif, hal ini terjadi akibat reaksi hipersensitifitas dari infestasi Otodectes

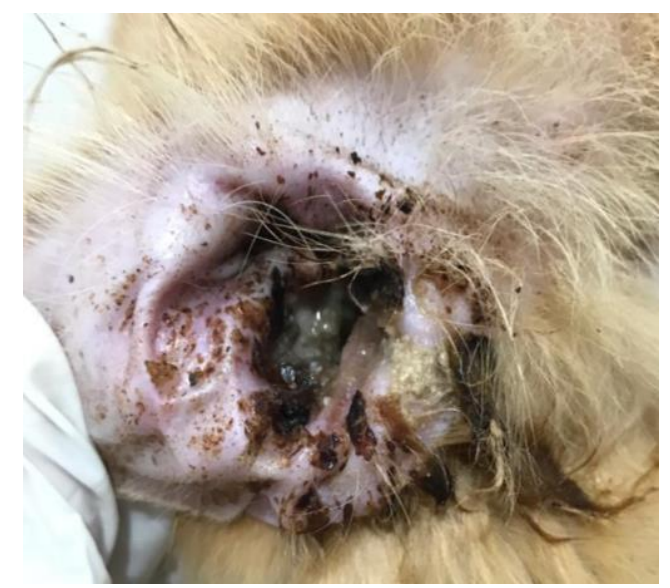

Gambar 3. Kondisi telinga bagian luar pasien hari ke-0 cynotis. Pada hari ke-3 terapi, teramati masih adanya kotoran telinga bewarna kuning kehitaman namun sudah tidak terlalu basah dan bau telinga sudah berkurang. Kondisi rambut disekitar telinga juga masih sedikit basah (Gambar 4). Aksi kucing menggaruk telinga masih aktif. Pada hari ke-5 terapi, teramati kotoran dan bau telinga sudah sangat berkurang. Kondisi rambut disekitar telinga kering serta aksi kucing menggaruk telinga sudah mulai berkurang (Gambar 5). Pada hari ke-7 terapi, teramati sudah tidak ada kotoran dan bau telinga. Kondisi rambut disekitar telinga kering serta aksi kucing menggaruk telinga sudah tidak ada (Gambar 6).

Pengamatan progres kesembuhan yang ditinjau dari skoring jumlah Otodectes cynotis dengan pemeriksaan ear swab yaitu pada hari ke-0 ditemukan banyak sekali Otodectes cynotis dan telur Otodectes cynotis dan diberi skoring (+++) (gambar 7). Hari ke-3 terapi, jumlah Otodectes cynotis dan telur Otodectes cynotis berkurang dan diberi skoring (++) (gambar 8). Hari ke-5 terapi, jumlah Otodectes cynotis dan telur Otodectes cynotis ditemukan sangat sedikit dan diberi skoring (+) (gambar 9). Hari ke-7 terapi, tidak ditemukan Otodectes cynotis dan telur Otodectes cynotis dan diberi skoring (-).

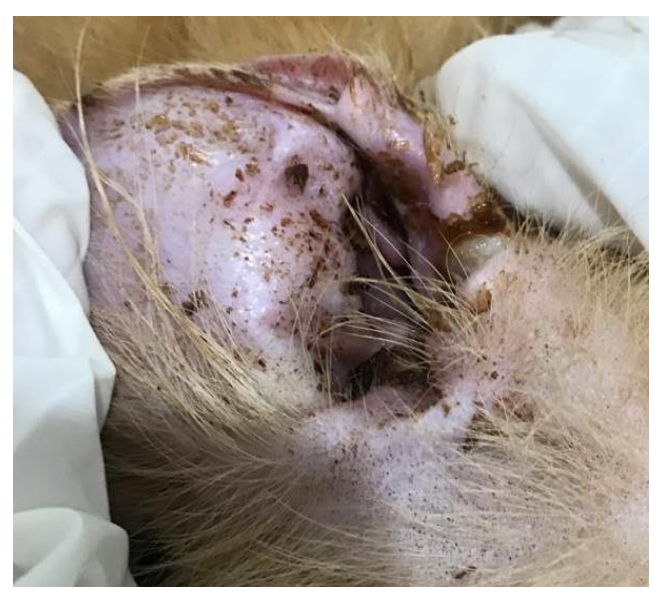

Gambar 4. Kondisi telinga bagian luar pasien hari ke-3 terapi 


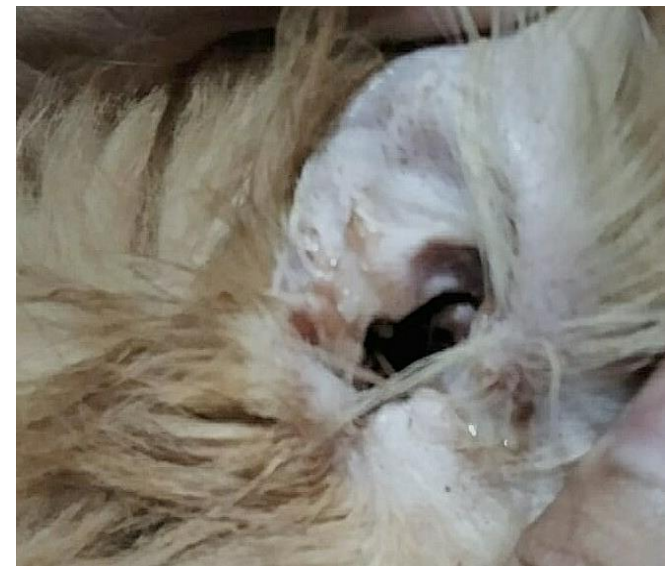

Gambar 5 Kondisi telinga bagian luar pasien hari ke-5 terapi

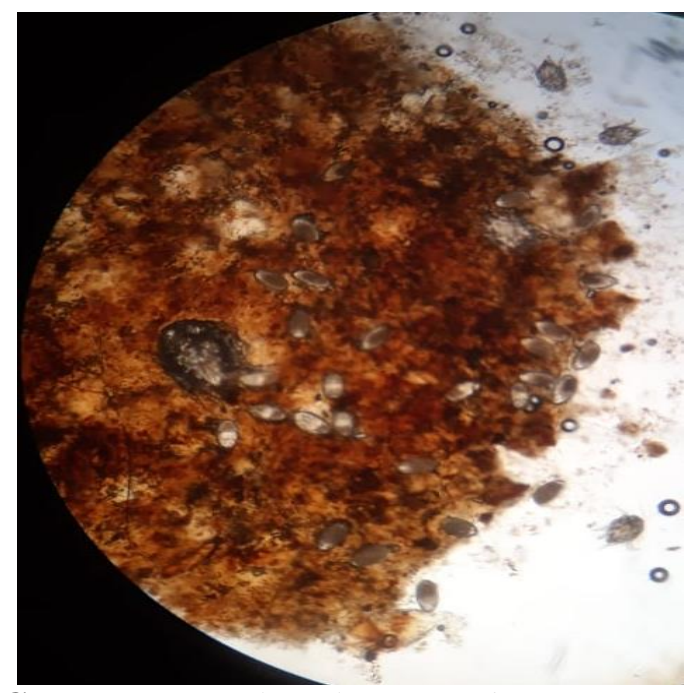

Gambar 7. Keberadaan Otodectes cynotis dan telur Otodectes cynotis pada hari ke-0, dengan skoring $(+++)$

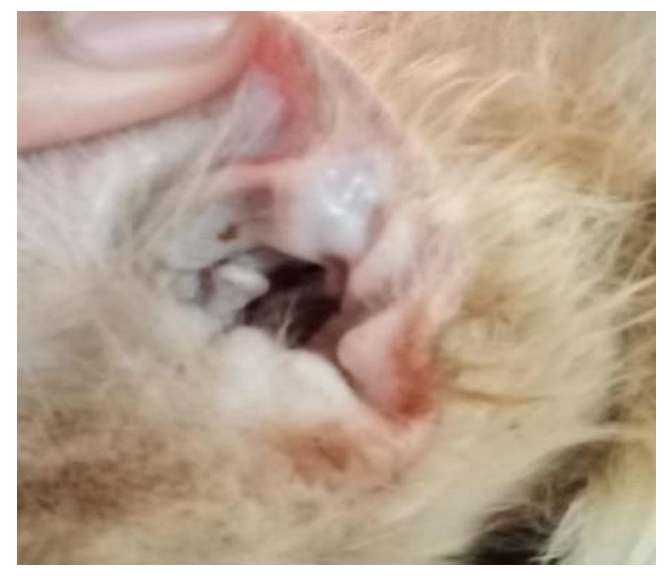

Gambar 6. Kondisi telinga bagian luar pasien hari ke-7 terapi

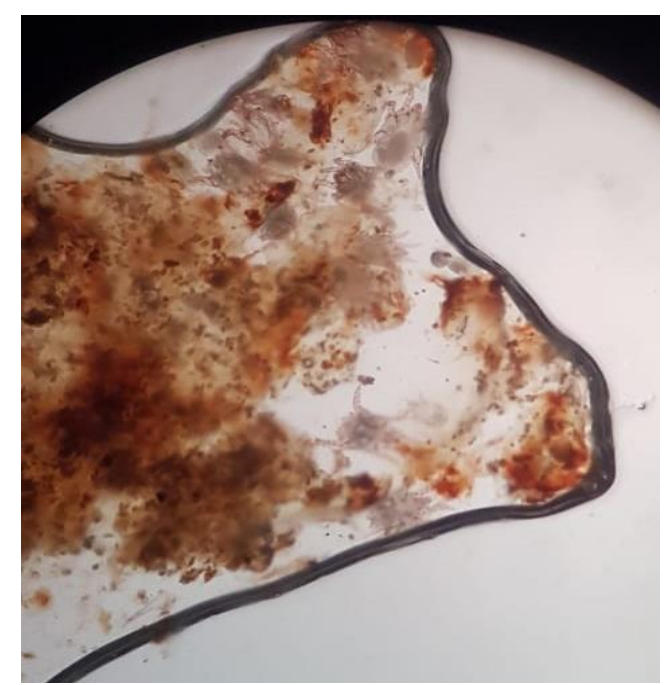

Gambar 8. Keberadaan Otodectes cynotis dan telur Otodectes cynotis pada hari ke-3 terapi, dengan skoring $(++)$

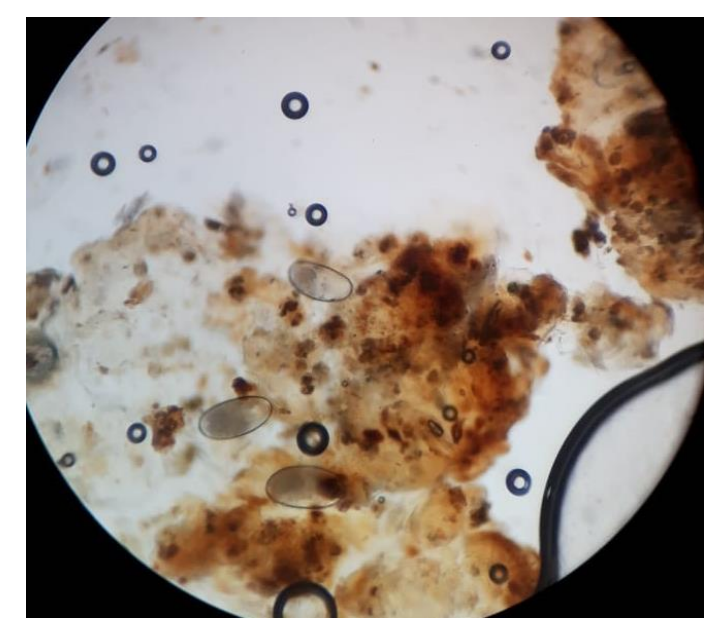

Gambar 9. Keberadaan Otodectes cynotis dan telur Otodectes cynotis pada hari ke-5 terapi, dengan skoring $(+)$ 
Terapi topikal yang diberikan adalah Ilium ${ }^{\circledR}$ ear drop dengan kandungan $5 \mathrm{mg} / \mathrm{ml}$ Dichlorophen, $5 \mathrm{mg} / \mathrm{ml}$ Piperonyl butoxide, dan 500 gram $/ \mathrm{ml}$ Pyrethrins, dan $5 \mathrm{mg} / \mathrm{ml}$ Lignocaine $\mathrm{HCl}$. Dichlorophen, Piperonyl butoxide, dan Pyrethrins memiliki aktivitas sebagai antimikroba, antifungal, serta antiparasit. Pyrethrins sebagai antiparasit memiliki efektifitas lebih baik pada aplikasi topikal dibandingkan dengan per oral.

Sinergisitas efek antara Piperonyl butoxide dan Pyrethrins terjadi melalui penghambatan enzim mikrosomal sitokrom P450 yang bertanggung jawab untuk memetabolisme piretroid (Susanto, et al., 2020; El Akkad et al., 2016). Kesembuhan otitis eksterna pada pasien terjadi akibat lisisnya mikroorganisme primer penyebab otitis eksterna yaitu Otodectes cynotis dan infeksi sekunder bakteri akibat aktivitas kandungan Ilium ${ }^{\circledR}$ ear drop.

Lignocaine $\mathrm{HCl}$ merupakan salah satu analgesik yang bekerja dengan memblokir saluran natrium pada membran sel neuron post-sinaptik, hal ini akan berdampak pada pencegahan depolarisasi jaringan saraf serta menghambat pembentukan dan penyebaran impuls saraf (Sogebi, et al., 2017; Bhargava et al., 2018). Efek analgesik Lignocaine $\mathrm{HCl}$ terlihat pada aksi menggaruk pasien yang berkurang pasca pemberian terapi.

\section{KESIMPULAN}

Diagnosa otitis eksterna dapat ditegakkan melalui pemeriksaan mikroskopik menggunakan ear swab dan sitologi ear serumen. Terapi topikal menggunakan Ilium ${ }^{\circledR}$ ear drop tiga tetes dua kali sehari memberikan respon yang baik pada pasien dengan otitis eksterna akibat penyebab primer infestasi Otodectes cynotis dan infeksi sekunder bakteri.

\section{REFERENSI}

Acar, A., Yipel, F.A. 2016. Factor related to the frequency of cat ear mites (Otodectes cynotis). Kafkas. Univ. Vet. Fak. Derg., 22(1), 75-78.

Bhargava, D., Koneru, G., Desphande, A., Desai, K., Dalsingh, V. 2018. Proposed mechasism of action for twin mix anaesthesia when used as intra-space pterygomandibular injection for inferior alveolar nerve block with emphasis on effects of perineural injection of dexamethasone. Adv. Hum. Biol., 8, 5053.

da Silva, J.T., Ferreira, L.C., Fernandes, M.M., Sousa, L.dM., Feitosa, T.F., Braga, F.R., Brasil, A.W.dM., Vilela, V.L.R. 2020. Prevalence and clinical aspects of Otodectes cynotis infestation in dogs and cats in the semi-arid region of Parabia, Brazil. Act. Sci. Vet., 48, 1725.

El Akkad, D.M.H., El-Gebaly, N.S.M., Yousof, H.A.S.A., Ismail, M.A.M. 2016. Electron microscopic alterations in Pediculus humanus capitis exposed to some pediculidal plant extracts. Korean J. Parasitol., 54(4), 527-532.

Kartini, C., Efendi, A., Herlina, Putra, M. AR. 2017. Catatan Dokter Hewan Pemeriksaan Fisik pada Mata, Telinga, Kardiorespirasi, dan Saluran Pencernaan. IPB Press, 12.

Siagian, T.B., Fikri, F.H. 2019. Infestasi ektoparasit pada kucing di klinik hewan Kabupaten Bogor. Seminar Nasional Teknologi Terapan Inovasi dan Rekayasa (SNT2R), Kendari, 1 Desember 2019. pp: 480-484.

Sogebi, E.A.O., Adeleye, Al., Babalola, S.A. 2017. Management of partial thicknes burn of the dorsum skin in a 3-year-old male German shaperd. Sakoto J. Vet. Sci., 15(1), 77-81.

Susanto, H., Kartikaningrum, M., Wahjuni, R.S., Warsito, S.H., Yuliani, M.G.A. 2020. Kasus scabies (Sarcoptes scabiei) pada kucing di klinik Intimedipet Surabaya. J. Bio. Pasca., 22(1), 37-45.

Taenzler, J., de Vos, C., Roepke, R.K.A., Hackeroth, A.R. 2018. Efficacy of fluralaner plus moxidectin (Bravecto® plus spot-on solution for cats) againts Otodectes cynotis infestasions in cats. Parasit. Vect., 11, 595. 